\title{
The Effect of Aerobic Exercise Duration on Affective Responses
}

\author{
Bruno R. R. Oliveira ${ }^{1}$, Tony M. Santos ${ }^{2}$, Leônidas M. Fagundes ${ }^{3}$, Sarah C. C. Generoso ${ }^{3}$, \\ Andréa C. Deslandes ${ }^{1}$ \\ ${ }^{I}$ Federal University of Rio de Janeiro, Rio de Janeiro, RJ \\ ${ }^{2}$ Pernambuco Federal University, Recife, PE \\ ${ }^{3}$ President Antônio Carlos University, Barbacena, $M G$
}

\begin{abstract}
*Corresponding Author: Bruno $\boldsymbol{R} \boldsymbol{R}$ Oliveira, Universidade Federal do Rio de Janeiro (UFRJ) - Av Venceslau Bras 71 - Botafogo; Rio de Janeiro - RJ, 22290-140. E-mail: brunoramalho87@gmail.com
\end{abstract}

\begin{abstract}
The objective was to verify the effect of exercise duration on affective responses. Fifteen men underwent two visits on a treadmill. During the first visit, a maximal incremental test was performed. During the second visit, the aerobic exercise session was performed; we recorded physiological variables and the affective response before, during and after the exercise session. The total number of records of the affective response was reduced and equalized into quintiles. A linear regression analysis showed an inverse relationship between exercise duration and affective response, which reduced at a rate of - 0.4 every 5 minutes of exercise $(r 2=0.97 ; p=0.001)$. An effect size analysis indicated a reduction of affective response from quintile $3 \Leftrightarrow 14$ minutes of exercise) to quintile $5(\approx 24$ minutes of exercise) compared with the affective response measured before exercise. The results indicate that the duration may influence the affective response during an aerobic exercise session.
\end{abstract}

Keywords: Pleasure, VO2, Feeling Scale, continuous exercise, respiratory compensation point

\section{INTRODUCTION}

A low physical fitness is associated with an increased risk for all-cause mortality [1]. Approximately $25 \%$ of the American adult population is physically inactive [2]. In addition, approximately $45 \%$ of individuals who start an exercise program drop out before completing the first six months [3]. Several factors may explain these facts, such as a low motivational level, reduced self-efficacy, lack of motor ability to perform sport movements, low exercise tolerance and dissatisfaction [4]. Therefore, the development of training strategies that focus on the exercise adherence are important.

Affective responses (pleasure/displeasure) is an important factor for behavioral change [5]. According to the Hedonic Theory, individuals tend to reproduce pleasant behaviors (positive affective responses) and to avoid unpleasant behaviors (negative affective responses) [6]. Therefore, it is possible that exercise sessions that provide positive affective responses increase the exercise adherence and vice-versa.
In this context, the lactate or ventilatory threshold may be used as a physiological marker for affective responses during aerobic exercise [7,8]. Aerobic exercise sessions performed at intensities above the lactate or ventilatory threshold are associated with negative affective responses, whereas exercise sessions performed at intensities below the lactate or ventilatory threshold are associated with positive affective responses [9]. The effect of aerobic exercise intensity was broadly discussed in the literature [10-12], however, it should be considered that an aerobic exercise session configuration is based on intensity and duration. Reed and Buck [13] performed a review to investigate the effects of exercise duration on psychological variables; however, the majority of the studies included in this review investigated mood responses instead of affective responses. Petruzzello and Landers [14] compared two aerobic exercise sessions with different durations (15 and $30 \mathrm{~min}$ ) in young men, and no differences were found between both conditions (15 and $30 \mathrm{~min}$ ). However, the affective responses were measured only pre-to-post exercise. 
Considering a possible influence of affective responses in exercise adherence, a better understanding on the effect of exercise duration on affective responses could contribute to the increase of affective responses in aerobic exercise sessions, increasing the likelihood of exercise adherence. Therefore, the objective of the present study was to verify the effect of exercise duration on affective responses. In general, the literature demonstrates that exercise sessions performed at high intensities are usually associated with uncomfortable perceptions (e.g., higher ratings of perceived exertion, pain, and excessive tiredness) resulting in negative affective responses $[9,15]$. Based on this premise, it is possible to hypothesize that the increase of exercise duration, and consequently, the increase of physiological discomfort would result in negative affective responses. Thus, our hypothesis is that the exercise duration would be inversely related to affective responses.

\section{METHODS}

This study was approved by the Institutional Ethics Committee. All procedures were performed in accordance to the Declaration of Helsinki.

\subsection{Participants}

Fifteen men from 18 to 45 years, classified as low risk for cardiovascular disease and with no diagnosis of mental disease were invited to participate. Individuals with musculoskeletal injuries or resting blood pressure above 139/89 mmHg were excluded.

\subsection{Experimental Design}

Participants performed a total of two experimental sessions. In the first session, informed consent and a Stratification Risk Questionnaire were applied and then participants' resting heart rate (HR), blood pressure and anthropometric measurements were recorded. Participants underwent an incremental exercise test to determine peak oxygen consumption ( $\mathrm{VO}_{2}$ Peak), maximal HR and the respiratory compensation point (RCP). In the second session, aerobic exercise was performed. Physiological and psychological variables were recorded before, during, and after the exercise. An interval of two to seven days between sessions was adopted, and participants were instructed to not use medications or to perform exercise 24 hours prior to the tests.

\subsection{Procedures}

\subsubsection{Anthropometry}

Body mass and height were measured (Filizola 31, Filizola SA, São Paulo, Brazil) to determine the body mass index (BMI). A skinfold caliper (SlimGuide, Rosscraft Innovations Inc., Vancouver, Canada) was used to measure skinfold thickness [16]. Then, the body fat percentage was estimated [17].

\subsubsection{Incremental Exercise Test}

An incremental exercise test was performed to determine $\mathrm{VO}_{2}$ Peak, RCP [18], and the maximal HR. After a $5 \mathrm{~min}$ warm-up at $5 \mathrm{~km} \cdot \mathrm{h}^{-}$ ${ }^{1}$, the treadmill speed was adjusted to $8.5 \mathrm{~km} \cdot \mathrm{h}^{-1}$ and maintained for 3 minutes. Then, the treadmill speed was increased to $1.5 \mathrm{~km} \cdot \mathrm{h}^{-1}$ at each 2 min stage. When the participant reached $16 \mathrm{~km} \cdot \mathrm{h}^{-1}$, the speed was maintained, and the treadmill slope was increased by $2 \%$ every 2 minutes until volitional fatigue. A HR monitor was used (RS800CX, Polar Electro OY, Kempele, Finland) to record the HR during the test. Gas exchange was recorded using a gas analyzer (Cortex Metalyzer II, Cortex Biophysik GmbH. Leipzig, Germany).

\subsubsection{Affective Response}

The Feeling Scale (FS) was used for the measurement of affective responses. The FS is a bipolar scale with ranges between -5 (Very bad) to +5 (Very good) and a zero value (Neutral). The FS was used because the construct measured in the present study was the core affect. Moreover, the FS is a single-item scale, allowing easy application during the exercise session.

\subsubsection{Aerobic exercise session}

In the second visit, an aerobic training session was performed at an intensity of $85 \%$ of RCP and a duration equivalent to $50 \%$ of the duration recommended by Santos et al. [19]. The duration was calculated based on the $\mathrm{VO}_{2}$ Peak using the following equation: Duration $($ min.session- 1$)=\left(\mathrm{VO}_{2}\right.$ Peak $\left.\times 0.89+5.35\right) \times$ 0.5 . For example, an individual with a $\mathrm{VO}_{2}$ Peak of $42 \mathrm{~mL} \cdot \mathrm{kg}^{-1} \cdot \mathrm{min}^{-1}$ should perform an exercise session of $21.3 \mathrm{~min}$. The gas exchange variables and the HR were continuously measured during the exercise session. The FS was measured 10 minutes before and 5 minutes after the exercise session. During the exercise session, the FS was measured every 3 minutes. 


\subsection{Statistical Analysis}

A descriptive analysis of the participants' and the exercise session characteristics was performed. The FS data was grouped into quintiles $(\mathrm{Q})$ to reduce and equalize the number of records to five. A linear regression was performed to verify the relationship between the FS responses and the exercise duration. A oneway ANOVA was performed to compare the FS responses across the different moments of measurements (pre, Q1, Q2, Q3, Q4, Q5, and post). An effect size analysis was performed to compare the FS responses obtained during and after the exercise session to the FS response obtained before the exercise session (the pre FS value was used as the reference for comparison). The effect size was classified as: $<0.20$, Trivial; 0.21 - 0.60, Small; $0.61-1.20$, Moderate; 1.21 - 2.00, Large; $2.01-4.00$, Very large; and > 4.00, Nearly perfect [20]. The confidence interval was established at $90 \%$ and was interpreted as suggested by Batterham and Hopkins [21]. In addition, considering the interindividual variability of the affective responses [22], a descriptive analysis was performed to identify the percentage of participants who reduced, maintained, or increased their FS responses from Q1 to Q5 of the exercise session. These data were calculated by subtracting the FS responses obtained in Q5 from the FS responses obtained in Q1.

\section{RESULTS}

The characteristics of participants were as follows: age $=24 \pm 4$ years; $\mathrm{VO}_{2}$ Peak $=47.9 \pm$ 7.4 mL.kg- ${ }^{1} \cdot \mathrm{min}^{-1} ; \mathrm{RCP}=80.3 \pm 4.5 \%$ of $\mathrm{VO}_{2}$ Peak; BMI $=24.2 \pm 2.5 \mathrm{~kg} \cdot \mathrm{m}^{-2}$; and body fat percentage $=10.8 \pm 4.5$. The aerobic exercise session presented an average $\mathrm{VO}_{2}$ of $71.8 \% \pm$ $7.5 \%$ of $\mathrm{VO}_{2}$ Peak, an average HR of $80.4 \% \pm$ $4.4 \%$ of the maximal HR, and an average duration of $23.9 \pm 3.2 \mathrm{~min}$.

Table1. Affective responses measured before, during and after the exercise session

\begin{tabular}{|l|l|l|l|}
\hline \multirow{2}{*}{ Moment } & \multicolumn{2}{|l|}{ Feeling Scale } & \multirow{2}{*}{ Post hoc (p value) } \\
\cline { 2 - 3 } & Mean & SD & \\
\hline Pre & 2.00 & 2.23 & - \\
\hline Q1 & 2.33 & 1.71 & - \\
\hline Q2 & 1.90 & 1.41 & - \\
\hline Q3 & 1.40 & 2.09 & - \\
\hline Q4 & 1.26 & 2.47 & Post $(0.040)$ \\
\hline Q5 & .80 & 2.54 & Post $(0.005)$ \\
\hline Post & 3.60 & 1.05 & Q4 (0.040); Q5 (0.005) \\
\hline \multicolumn{2}{|l|}{$Q-$ quintiles } \\
\hline
\end{tabular}

The mean and standard deviation values of FS are reported in Table 1. The one-way ANOVA showed a significant increase of FS only after the exercise session $(\mathrm{F}(6,98)=3.089 ; \mathrm{p}=$ 0.008 ) as presented in Table 1 . The FS presented a reduction rate of -0.4 every 5 minutes as demonstrated by the equation obtained from the linear regression $(\mathrm{FS}=$ $0.0773 \times$ exercise duration $(\mathrm{min})+2.65 ; \mathrm{r} 2=$ $0.97, p=0.001$ ) as presented in Figure 1.

The effect size analysis showed a Trivial effect of Q1 and Q2 of FS compared with the pre value. However, from Q3 $(\approx 15$ minutes of exercise) to Q5 ( $\approx 24$ minutes of exercise) the FS presented a reduction compared with the pre value with an effect size classified as Small. Additionally, we observed an increase of postexercise FS response compared with preexercise FS response with an effect size classified as Moderate. According to the inferences suggested by Batterham and Hopkins considering not only the effect size but also the confidence intervals [21], the comparisons between Q1, Q2, Q3, and Q4 and the pre value of FS may be interpreted as "Unclear". The comparison between Q5 and the pre value of FS may be interpreted as "Possibly harmful", and the comparison between the pre and post values of FS may be interpreted as "Almost certainly beneficial" (Figure 2). Together, these results indicate that the increase of exercise duration resulted in a reduction of FS during the exercise session and an increase of FS response after the exercise session.

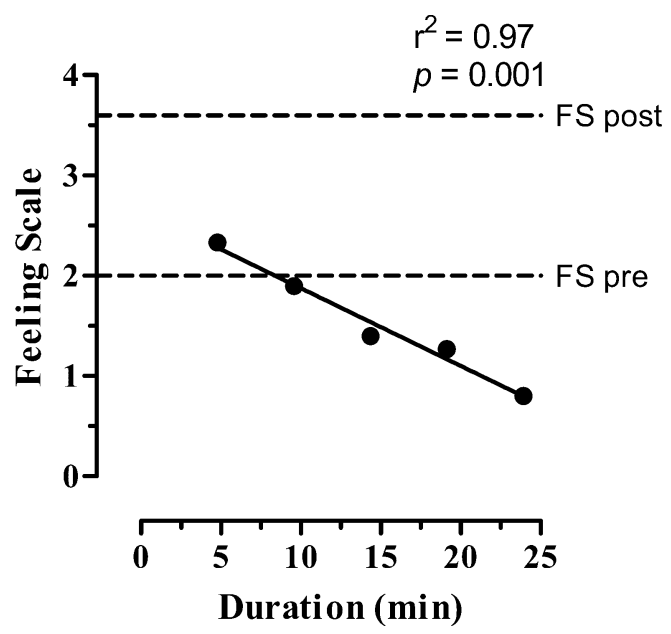

Figure1. Linear regression between FS and exercise duration. Dashed lines represents the FS response obtained pre and post exercise. 


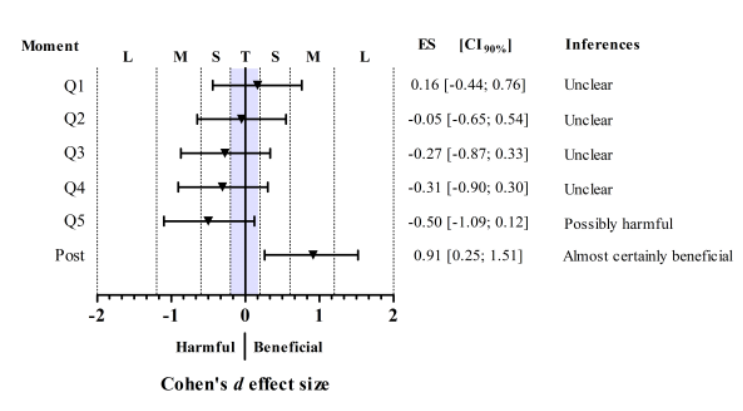

Figure2. The effect size for FS responses. The pre FS response is the reference category represented by zero. Gray area represents trivial effect sizes. ES effect size; $C I$ - confidence interval; $T$ - trivial; $S$ small; $M$ - moderate; $L$ - large; and $Q$ - quintiles

The individual variation analysis showed that nine participants $(60 \%)$ reduced their FS response, one participant (7\%) maintained their FS response, and five participants (33\%) increased their FS response during the exercise session.

\section{DISCUSSION}

The results of the present study suggest that prolonging the duration of exercise results in a reduction of affective response measured by the FS, which corroborates with our hypothesis that an increase in exercise duration leads to a reduction of affective response, indicating that the duration of exercise influences the affective response. On the other hand, an increase of FS was observed after the exercise session, indicating a rebound effect, which may be explained by the opponent-process theory [23].

This result could be explained by prolonged physiological stress generated by exercise. It has been discussed that both the intensity and duration of exercise may affect the levels of cortisol [24], which is associated with negative affective responses [25]. On the other hand, it is possible that exercise sessions with longer durations (usually performed by long-distance runners) create positive feelings of well-being, euphoria, analgesia, happiness, and energy. This premise is based on a concept known as "runner 's high" [26] and could be explained by the hypothesis of the endocannabinoid system [27] as well as by opioidergic mechanisms [26]. However, future studies are needed to clarify this issue.

In a previous study, Kilpatrick et al. [28] investigated the effect of two aerobic exercise sessions equalized by the total work. One session was performed with shorter duration and higher intensity than the other. The authors found that the longer session resulted in higher affective response; however, the objective of this study was to compare the affective responses in two aerobic sessions at different intensities and durations. In another study, Petruzzello and Landers [14] compared the effect of two aerobic exercise sessions of different durations (15 and $30 \mathrm{~min}$ ) in affective responses and found no significant differences between the two conditions. However, this study compared two different durations and used the PANAS questionnaire for the measurement of affect. Thus, considering the methodological differences between this study and previous studies, the results cannot be compared interchangeably.

In this study, $60 \%$ of participants presented a reduction by at least one point in FS during the exercise session. Williams et al. [29] already demonstrated that an increase of one point in the FS may be associated with an increase of $38 \mathrm{~min}$ weekly aerobic exercise. Therefore, it is possible to hypothesize that the reduction of affective response would be associated with a lower quantity of weekly exercise performed by an individual throughout an aerobic training program.

This study has limitations that should be considered when interpreting the results. In a review, Ekkekakis et al. [9] discussed the importance of the lactate/ventilatory threshold as a physiological marker for affective response. This study investigated the effect of exercise duration in affective responses in an aerobic exercise session performed at an intensity below the lactate/ventilatory threshold. It is possible that the FS presents a different pattern during an exercise session performed at an intensity above the lactate/ventilatory threshold.

Several recommendations for aerobic training sessions are regularly published in the scientific literature [19,30-32]. However, these recommendations do not consider aspects related to affective responses. Thus, this study contributes to the understanding of the affective response pattern during an aerobic exercise session, and in conjunction with other studies that have addressed the effect of exercise intensity [9,33-35], the study could facilitate future recommendations that address the emotional context of the practitioners.

\section{CONClusion}

In summary, the present study showed that prolonging exercise duration may negatively influence the affective response of individuals, 
even if the exercise is performed at an intensity below the lactate/ventilatory threshold. Thus, the prescription of aerobic exercise sessions aimed to improve the affective responses must consider not only the intensity but also the duration of the exercise. Therefore, future aerobic prescription recommendations should include suggestions of intensity and duration with the objective of the improvement of affective responses.

\section{ACKNOWLEDGEMENTS}

Bruno Ribeiro Ramalho Oliveira has a scholarship of CNPq.

\section{REFERENCES}

[1] Blair S. N., Physical inactivity: the biggest public health problem of the 21st century, Br J Sports Med. 43(1), 1-2 (2009).

[2] Schenck A., Andrulis D. P., Bartram J., Catlin B. B., Coburn A., et al. (2014) America's health rankings: a call to action for individuals \& their communities. Minnetonka: United Health Foundation. $146 \mathrm{p}$.

[3] Marcus B. H., Williams D. M., Dubbert P. M., Sallis J. F., King A. C., et al., Physical activity intervention studies: what we know and what we need to know: a scientific statement from the American Heart Association Council on Nutrition, Physical Activity, and Metabolism (Subcommittee on Physical Activity); Council on Cardiovascular Disease in the Young; and the Interdisciplinary Working Group on Quality of Care and Outcomes Research, Circulation. 114(24), 2739-2752 (2006)

[4] Dalle Grave R., Calugi S., Centis E., El Ghoch M.and Marchesini G., Cognitive-behavioral strategies to increase the adherence to exercise in the management of obesity, $\mathrm{J}$ Obes. 2011(348293 (2011)

[5] Elsangedy H. M., Santos B. V., Almeida F. A. M., Krinski K., Nunes R. F. H., et al., Percepção de prazer/desprazer de mulheres com sobrepeso e obesidade durante caminhada em intensidade autosselecionada, Rev Bras Ativ Fís Saúde. 15(4), 205-210 (2010).

[6] Williams D. M., Exercise, affect, and adherence: an integrated model and a case for self-paced exercise, J Sport Exerc Psychol. 30(5), 471-496 (2008).

[7] Parfitt G., Rose E. A.and Burgess W. M., The psychological and physiological responses of sedentary individuals to prescribed and preferred intensity exercise, $\mathrm{Br} \mathrm{J}$ Health Psychol. 11(Pt 1), 39-53 (2006)

[8] Lind E., Joens-Matre R. R.and Ekkekakis P., What intensity of physical activity do previously sedentary middle-aged women select? Evidence of a coherent pattern from physiological, perceptual, and affective markers, Prev Med. 40(4), 407-419 (2005).

[9] Ekkekakis P., Parfitt G.and Petruzzello S. J., The pleasure and displeasure people feel when they exercise at different intensities: decennial update and progress towards a tripartite rationale for exercise intensity prescription, Sports Med. 41(8), 641-671 (2011).

[10] Krinski K., Elsangedy H. M., Buzzachera C. F., Colombo H., Nunes R. F. H., et al., Resposta afetiva entre os gêneros durante caminhada em ritmo auto-selecionado na esteira., Rev Bras Ativ Fís Saúde. 13(1), 37-43 (2008).

[11] Ekkekakis P., Let them roam free? Physiological and psychological evidence for the potential of self-selected exercise intensity in public health, Sports Med. 39(10), 857-888 (2009).

[12] Krinski K., Elsangedy H. M., Buzzachera C. F., Colombo H., Santos B. V., et al., Influência da adiposidade nas respostas fisiológicas e afetivas na caminhada de ritmo autosselecionado, Rev Bras Cineantropom Desempenho Hum. 12(2), 120-126 (2009).

[13] Reed J.and Buck S., The effect of regular aerobic exercise on positivie-activated affect: A meta-analysis, Psychol Sport Exerc. 10(6), 581594 (2009).

[14] Petruzzello S. J.and Landers D. M., State anxiety reduction and exercise: does hemispheric activation reflect such changes?, Anxiety Stress Coping. 6(4), 301-310 (1994).

[15] Oliveira B. R., Deslandes A. C., Thompson W. R., Terra B. S.and Santos T. M., Comparison of two proposed guidelines for aerobic training sessions, Percept Mot Skills. 115(2), 645-660 (2012).

[16] Jackson A. S.and Pollock M. L., Generalized equations for predicting body density of men, Br J Nutr. 40(3), 497-504 (1978).

[17] Siri W. E. (1961) Body composition from fluid spaces and density. In: A BJeH, editor. Techniques of Measuring Body Composition. Washington D.C: National Academy of Science. pp. 233-244.

[18] Beaver W. L., Wasserman K.and Whipp B. J., A new method for detecting anaerobic threshold by gas exchange, J Appl Physiol (1985). 60(6), 2020-2027 (1986).

[19] Santos T. M., Gomes P. S., Oliveira B. R., Ribeiro L. G.and Thompson W. R., A new strategy for the implementation of an aerobic training session, J Strength Cond Res. 26(1), 87-93 (2012).

[20] Hopkins W. G. (2002) A Scale of Magnitudes for Effect Statistics. 
[21] Batterham A. M.and Hopkins W. G., Making meaningful inferences about magnitudes, Int J Sports Physiol Perform. 1(1), 50-57 (2005).

[22] Van Landuyt L. M., Ekkekakis P., Hall E. E.and Petruzzello S. J., Throwing the mountains into the lakes: on perils of nomothetic conceptions of the exercise-affect relationship, J Sport Exerc Psychol. 22(3), 208234 (2000).

[23] Solomon R. L., The opponent-process theory of acquired motivation: the costs of pleasure and the benefits of pain, Am Psychol. 35(8), 691712 (1980).

[24] Jacks D. E., Sowash J., Anning J., McGloughlin T.and Andres F., Effect of exercise at three exercise intensities on salivary cortisol, J Strength Cond Res. 16(2), 286-289 (2002).

[25] Frankenhauser M., The psychophysiology of workload, stress, and health: comparison between sexes, Ann Behav Med. 13(4), 197204 (1991).

[26] Boecker H., Sprenger T., Spilker M. E., Henriksen G., Koppenhoefer M., et al., The runner's high: opioidergic mechanisms in the human brain, Cereb Cortex. 18(11), 2523-2531 (2008).

[27] Dietrich A.and McDaniel W. F., Endocannabinoids and exercise, $\mathrm{Br} \mathrm{J}$ Sports Med. 38(536-541 (2004).

[28] Kilpatrick M., Kraemer R., Bartholomew J., Acevedo E.and Jarreau D., Affective responses to exercise are dependent on intensity rather than total work, Med Sci Sports Exerc. 39(8), 1417-1422 (2007).
[29] Williams D. M., Dunsiger S., Ciccolo J. T., Lewis B. A., Albrecht A. E., et al., Acute Affective Response to a Moderate-intensity Exercise Stimulus Predicts Physical Activity Participation 6 and 12 Months Later, Psychol Sport Exerc. 9(3), 231-245 (2008).

[30] ACSM (2010) ACSM's Guidelines for exercise testing and prescription. Baltimore (MD): Lippincott Williams \& Wilkins. 400 p.

[31] ACSM (2013) ACSM's Guidelines for exercise testing and prescription. Baltimore (MD): Lippincott Williams \& Wilkins. 480 p.

[32] Garber C. E., Blissmer B., Deschenes M. R., Franklin B. A., Lamonte M. J., et al., American College of Sports Medicine position stand. Quantity and quality of exercise for developing and maintaining cardiorespiratory, musculoskeletal, and neuromotor fitness in apparently healthy adults: guidance for prescribing exercise, Med Sci Sports Exerc. 43(7), 1334-1359 (2011).

[33] Parfitt G., Alrumh A.and Rowlands A. V., Affect-regulated exercise intensity: does training at an intensity that feels 'good' improve physical health?, J Sci Med Sport. 15(6), 548553 (2012).

[34] Rose E. A.and Parfitt G., A quantitative analysis and qualitative explanation of the individual differences in affective responses to prescribed and self-selected exercise intensities, J Sport Exerc Psychol. 29(3), 281-309 (2007).

[35] Sheppard K. E.and Parfitt G., Acute affective responses to prescribed and self-selected exercise intensities in young adolescent boys and girls, Pediatr Exerc Sci. 20(2), 129-141 (2008).

Citation: Bruno R. R. Oliveira et al. The Effect of Aerobic Exercise Duration on Affective Responses. ARC Journal of Neuroscience. 2017; 2(2):10-15. doi:dx.doi.org/10.20431/2456-057X.0202004.

Copyright: (C) 2017 Authors. This is an open-access article distributed under the terms of the Creative Commons Attribution License, which permits unrestricted use, distribution, and reproduction in any medium, provided the original author and source are credited. 